\title{
Effect of Acute and Chronic Simvastatin Treatment on Post-Ischemic Contractile Dysfunction in Isolated Rat Heart
}

\author{
O. SZÁRSZOI ${ }^{1,2}$, J. MALÝ ${ }^{1,2}$, P. OŠŤÁDAL ${ }^{3}$, I. NETUKA ${ }^{1,2}$, J. BEŠÍK $^{1,2}$, F. KOLÁ $\check{R}^{2}$, \\ B. OŠŤÁDAL ${ }^{2}$
}

Centre for Cardiovascular Research, ${ }^{1}$ Department of Cardiovascular Surgery, Institute for Clinical and Experimental Medicine and ${ }^{2}$ Institute of Physiology, Academy of Sciences of the Czech Republic, ${ }^{3}$ Department of Cardiology, Na Homolce Hospital, Prague, Czech Republic

Received March 20, 2008

Accepted July 8, 2008

\section{Summary}

Statins are powerful lipid-lowering drugs, widely used in patients with hyperlipidemia and coronary artery disease. It was found, however, that statins appear to have a pleiotropic effect beyond their lipid-lowering ability. They exert anti-inflammatory, antithrombotic and antioxidant effects, increase nitric oxide production and improve endothelial dysfunction. The aim of our study was to examine the effect of chronic and acute treatment with simvastatin on the contractile function of the isolated perfused rat heart after ischemia/reperfusion injury. Contractile function was measured on isolated rat hearts, perfused according to Langendorff under constant pressure. The hearts were subjected to $20 \mathrm{~min}$ of global ischemia, followed by $40 \mathrm{~min}$ of reperfusion. To investigate the acute effect, simvastatin at a concentration of $10 \mu \mathrm{mol} / \mathrm{l}$ was added to the perfusion solution during reperfusion. In chronic experiments the rats were fed simvastatin at a concentration of $10 \mathrm{mg} / \mathrm{kg}$ for two weeks before the measurement of the contractile function. Acute simvastatin administration significantly increased reparation of the peak of pressure development $\left[(+\mathrm{dP} / \mathrm{dt})_{\max }\right](52.9 \pm 8.2 \%)$ after global ischemia, as compared with the control group (28.8 $\pm 5.2 \%)$. Similar differences were also observed in the time course of the recovery of $\left[(+\mathrm{dP} / \mathrm{dt})_{\max }\right]$. Chronic simvastatin was without any protective effect. Our results reveal that the acute administration of simvastatin during reperfusion, unlike the chronic treatment, significantly reduced contractile dysfunction induced by ischemia/reperfusion injury. This supports the idea of possible cardioprotective effect of statin administration in the first-line therapy of the acute coronary syndrome.

\section{Key words}

Simvastatin • Isolated rat heart • Ischemia/reperfusion injury • Acute and chronic treatment

\section{Corresponding author}

Ondrej Szárszoi, Department of Cardiovascular Surgery, Institute for Clinical and Experimental Medicine, Vídeňská 1958/9, 14021 Prague 4, Czech Republic. Fax: 420261081362 . E-mail: onsz@medicon.cz

Statins (3-hydroxy-3-methylglutaryl coenzyme A reductase inhibitors) lower cholesterol level and are widely used in patients with hyperlipidemia and coronary artery disease. Statins reduce cardiovascular morbidity and mortality in a number of large clinical trials (LIPID Study Group 1998, Scandinavian Simvastatin Survival Study Group 1994, Sacks et al. 1996). During the past decade it was found that statins appear to have a pleiotropic effect beyond their lipid-lowering ability. It was demonstrated that they exert anti-inflammatory, antithrombotic, and antioxidant effects, increase nitric oxide production or improve endothelial dysfunction (Ošt'ádal 2006). Furthermore, statins can reduce experimental ischemia/reperfusion injury expressed as myocardial infarct size (Di Napoli et al. 2001, Lefer et al. 2001, Jones et al. 2002, Wayman et al. 2003, Tiefenbacher et al. 2003, Yamakuchi et al. 2005) or incidence of severe ventricular ischemic arrhythmias (Chen et al. 2007). To our best knowledge, there are no 
Table 1. Effects of chronic and acute simvastatin treatment on baseline contractile parameters and coronary flow of the isolated perfused hearts of rats.

\begin{tabular}{lccccc}
\hline & $\mathbf{n}$ & $\begin{array}{c}(+\mathbf{d P} / \mathbf{d t})_{\max } \\
(\mathbf{m m H g} / \mathbf{s})\end{array}$ & $\begin{array}{c}\text { LVDevP } \\
(\mathbf{m m H g})\end{array}$ & $\begin{array}{c}\text { LVDP } \\
(\mathbf{m m H g})\end{array}$ & $\begin{array}{c}\mathbf{C F} \\
(\mathbf{m l} / \mathbf{m i n} / \mathbf{g})\end{array}$ \\
\hline Control & 7 & $3913 \pm 262$ & $113.0 \pm 7.3$ & $5.8 \pm 1.5$ & $16.8 \pm 0.5$ \\
Acute statin & 7 & $3773 \pm 363$ & $113.1 \pm 6.6$ & $8.9 \pm 0.8$ & $15.9 \pm 0.7$ \\
Chronic statin & 6 & $3820 \pm 382$ & $117.9 \pm 7.0$ & $7.3 \pm 1.1$ & $17.1 \pm 0.4$ \\
\hline
\end{tabular}

$(+\mathrm{dP} / \mathrm{dt})_{\max }$, peak rate of pressure development; LVDevP, left ventricular developed pressure; LVDP, left ventricular diastolic pressure; $\mathrm{CF}$, coronary flow; $n$, number of animals. Values are means \pm S.E.M.; $* P<0.05$ vs. corresponding controls.

studies which compare the effect of chronic and acute statin treatment on post-ichemic contractile dysfunction in the isolated heart. Therefore, the aim of our study was to examine the effect of chronic and acute administration of simvastatin on the recovery of contractile function of the isolated perfused rat hearts after ischemia/reperfusion injury.

Adult male Wistar rats weighing 280 to $350 \mathrm{~g}$ were used. The investigations were performed in accordance with the Guide for Care and Use of Laboratory Animals published by the US National Institutes of Health (NIH Publication No. 85-23, revised 1996). The rats were anesthetized with intraperitoneal sodium pentobarbital $(60 \mathrm{mg} / \mathrm{kg})$. Their hearts were perfused by the Langendorff technique under constant pressure $\left(100 \mathrm{~cm} \mathrm{H}_{2} \mathrm{O}\right)$ with non-recirculating KrebsHenseleit solution containing (mmol/l): $\mathrm{NaCl} 118, \mathrm{KCl}$ 4.7, $\mathrm{CaCl}_{2} 1.25, \mathrm{MgSO}_{4} 1.2, \mathrm{NaHCO}_{3} 25.0, \mathrm{KH}_{2} \mathrm{PO}_{4} 1.2$ and glucose 7.0. The solution was saturated with $95 \% \mathrm{O}_{2}$ and $5 \% \mathrm{CO}_{2}(\mathrm{pH} 7.4)$ and maintained at $37{ }^{\circ} \mathrm{C}$. The left ventricle was vented at the apex and stimulated at 300 beats/min with platinum electrodes attached to the base of the right ventricle. Contractile function (left ventricular systolic - LVSP, diastolic - LVDP and developed pressure - LVDevP, and the peak rate of pressure development $\left.(+\mathrm{dP} / \mathrm{dt})_{\max }\right)$, was measured with a nonelastic balloon inserted into the left ventricle (Bešík et al. 2007). Coronary flow was measured by timed collection of coronary effluent. After $25 \mathrm{~min}$ of stabilization, the hearts were subjected to $20 \mathrm{~min}$ of global ischemia followed by $40 \mathrm{~min}$ of reperfusion. After restoration of flow, the functional parameters were recorded at 5-min intervals and their recovery was expressed as percentage of initial pre-ischemic values. To investigate the acute effect of statins, simvastatin at a concentration of 10 $\mu \mathrm{mol} / 1$ was added to the perfusion solution at the beginning of reperfusion. Simvastatin (Sigma) was diluted in $0.5 \mathrm{ml}$ of $100 \%$ ethanol, mixed with $0.75 \mathrm{ml}$ of
$0.1 \mathrm{~mol} / \mathrm{l} \mathrm{NaOH}$, heated to $50^{\circ} \mathrm{C}$ for $2 \mathrm{~h}$, neutralized with $0.1 \mathrm{~mol} / \mathrm{l} \mathrm{HCl}$ to $\mathrm{pH} 7.2$, and adjusted with deionized water to the final concentration. Control hearts were treated in the corresponding manner with a solution without simvastatin. In the chronic experimental group the rats were fed simvastatin at a concentration of $10 \mathrm{mg} / \mathrm{kg} /$ day for two weeks before experiment. Daily dose of the laboratory diet with statin was weighed and its consumption controlled by repeated weighing.

The results are expressed as means \pm S.E.M. One-way ANOVA or ANOVA for repeated measures and subsequent Student-Newman-Keuls test were used for comparison of differences between groups. Differences were assumed as statistically significant when $P<0.05$.

Baseline preischemic values of contractile parameters and coronary flow did not differ between control, acute and chronic simvastatin-treated hearts (Table 1). Acute simvastatin administration during reperfusion significantly increased the maximum recovery of $(+\mathrm{dP} / \mathrm{dt})_{\max }$ to $52.9 \pm 8.2 \%$ of preischemic value compared to the control group (28.8 $55.2 \%)$ (Fig. 1A). The same differences were observed also in the time course of the recovery of $(+\mathrm{dP} / \mathrm{dt})_{\max }$ (Fig. 1B). Similar results were also found in LVDP $(56.9 \pm 8.6 \%$ of preischemic value vs. $29.5 \pm 6.5 \%, \mathrm{P}<0.05)$. Chronic simvastatin treatment was without any protective effect.

Our results show that acute administration of simvastatin during reperfusion significantly reduced the contractile dysfunction. However, this protective effect of statins was not present after chronic treatment. It was shown previously that acute treatment of animals with statins prior to the onset of myocardial ischemia reduced the infarct size in mice (Lefer et al. 2001, Jones et al. 2002, Yamakuchi et al. 2005), rats (Di Napoli et al. 2001, Wayman et al. 2003, Tiefenbacher et al. 2003), dogs (Sanada et al. 2004) or pigs (Lazar et al. 2003). 

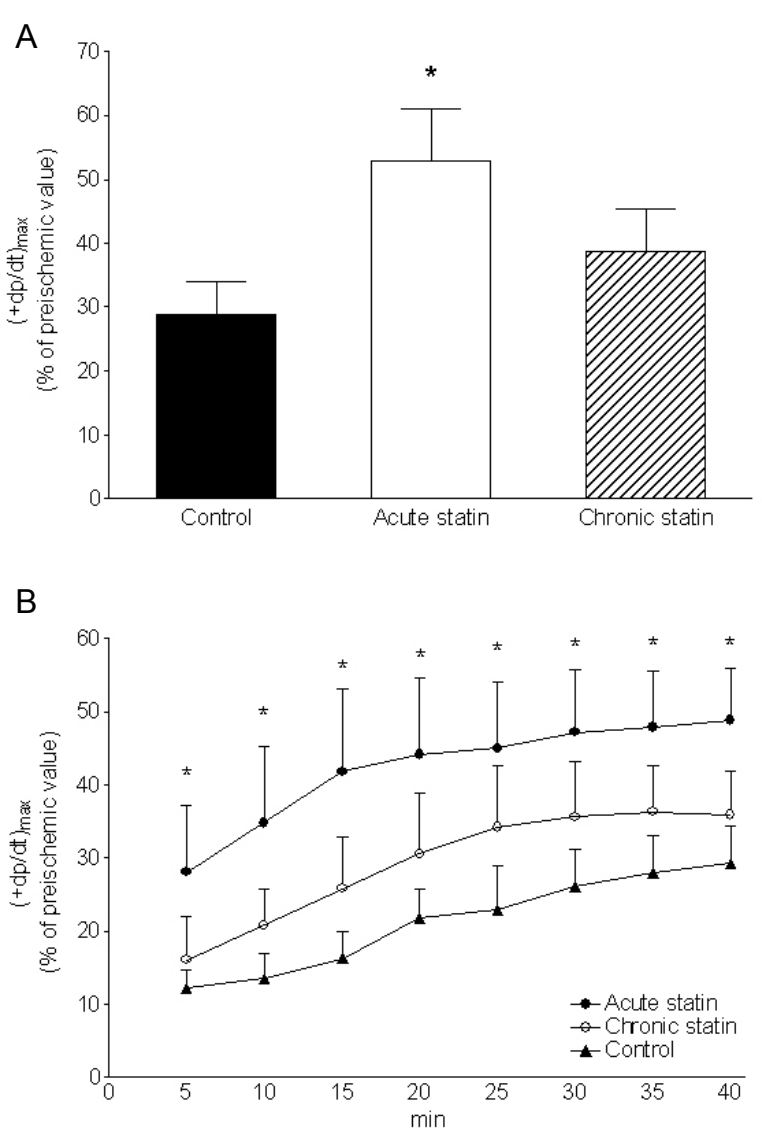

Fig. 1. The maximum recovery of the peak rate of pressure development $(+d P / d t)_{\max }(A)$ and time course of $(+d P / d t)_{\max }(B)$ during reperfusion in the control, acute and chronically simvastatin-treated treated hearts. Values are means \pm S.E.M.

While the above experimental studies demonstrated a protective effect of prophylactic therapy, they did not simultaneously address the question whether the animals with acute myocardial infarction might also benefit from the initiation of statin therapy during reperfusion. There are only a few papers dealing with this particular issue. Zheng and $\mathrm{Hu}$ (2006) found on the isolated rat heart that simvastatin added to the perfusion solution during reperfusion improved post-ischemic contractile recovery after $15 \mathrm{~min}$ ischemia. Bell and Yellon (2003) demonstrated the beneficial effect of atorvastatin (reduction of infarct size) administered at the time of reperfusion in the isolated perfused mouse heart. Finally, Wolfrum et al. (2004) showed in their in vivo study that simvastatin administered intravenously $3 \mathrm{~min}$ before restoration of flow significantly decreased infarct size in rats. On the other hand, chronic treatment of rats with simvastatin for two weeks did not change the severity of the contractile dysfunction in the isolated hearts in our study. Our results are in agreement with those of Mensah et al. (2005) showing that the infarct size lowering effect of atorvastatin, when given for less than three days before ischemia/reperfusion, is lost, when administered chronically for one or two weeks before the ischemic insult. Nevertheless, it seems that the effect of chronic statin treatment depends not only on the duration of treatment but also on the end-point of the ischemia/reperfusion injury. Chen et al. (2007) found that chronic administration of pravastatin for 22 days before the ischemic insult in the anesthetized rats reduced the incidence of ventricular fibrillations.

The protective effect of acute statin treatment against ischemia/reperfusion injury is well documented but its mechanism is still under investigation. The molecules that appear to play an important role in this protective mechanism are phosphatidylinositol-3-kinase (Bell and Yellon 2003, Wolfrum et al. 2004), nitric oxide synthase 3 (Jones et al. 2002, Tiefenbacher et al. 2003, Wolfrum et al. 2004), ATP-dependent potassium channels (Tavackoli et al. 2004) or PTEN (phosphatase and tensin homolog deleted on chromosome 10) a protein phosphatase known to inhibit the function of phosphatidylinositol-3-kinase (Mensah et al. 2005).

In conclusion, statins have an unambiguous cholesterol-independent cardioprotective effect that can be lost after chronic treatment. These results support the idea of possible cardioprotective effect of statin administration in the first-line therapy of acute coronary syndrome.

\section{Acknowledgement}

This study was supported by grant from the Ministry of Education of the Czech Republic 1M0510, grant AV0Z 50110509 , and grant of the Czech Ministry of Health, Nr. 0000064203 .

\section{Conflict of Interest}

There is no conflict of interest.

\section{References}

BELL RM, YELLON DM: Atorvastatin, administered at the onset of reperfusion, and independent of lipid lowering, protects the myocardium by up-regulating a pro-survival pathway. J Am Coll Cardiol 41: 508-515, 2003. 
BEŠÍK J, SZÁRSZOI O, KUNEŠ J, NETUKA I, MALÝ J, KOLÁŘ F, PIRK J, OŠŤÁDAL B: Tolerance to acute ischemia in adult male and female spontaneously hypertensive rats. Physiol Res 56: 267-274, 2007.

CHEN J, SHEN H, NAGASAWA Y, MITSUI K, TSURUGI K, HASHIMOTO K: Pravastatin inhibits arrhythmias induced by coronary artery ischemia in anesthetized rats. J Pharmacol Sci 103: 317-322, 2007.

DI NAPOLI P, ANTONIO TACCARDI A, GRILLI A, SPINA R, FELACO M, BARSOTTI A, DE CATERINA R: Simvastatin reduces reperfusion injury by modulating nitric oxide synthase expression: an ex vivo study in isolated working rat hearts. Cardiovasc Res 51: 283-293, 2001.

JONES SP, GIBSON MF, RIMMER DM, GIBSON TM, SHARP BR, LEFER DJ: Direct vascular and cardioprotective effects of rosuvastatin, a new HMG-CoA reductase inhibitor. J Am Coll Cardiol 40: 1172-1178, 2002.

LAZAR HL, BAO Y, ZHANG Y, BERNARD SA: Pretreatment with statins enhances myocardial protection during coronary revascularization. J Thorac Cardiovasc Surg 125: 1037-1042, 2003.

LEFER DJ, SCALIA R, JONES SP, SHARP BR, HOFFMEYER MR, FARVID AR, GIBSON MF, LEFER AM: HMG-CoA reductase inhibition protects the diabetic myocardium from ischemia-reperfusion injury. FASEB $J$ 15: 1454-1456, 2001.

LIPID STUDY GROUP: Prevention of cardiovascular events and death with pravastatin in patients with coronary heart disease and a broad range of initial cholesterol levels. N Engl J Med 339: 1349-1357, 1998.

MENSAH K, MOCANU MM, YELLON DM: Failure to protect the myocardium against ischemia/reperfusion injury after chronic atorvastatin treatment is recaptured by acute atorvastatin treatment: a potential role for phosphatase and tensin homolog deleted on chromosome ten? J Am Coll Cardiol 45: 1287-1291, 2005.

OŠŤÁDAL P: Statins in the Therapy of Acute Coronary Syndrome. Focus on Statin Research. Nova Science Publisher, edited by WONG BA, New York, 2005.

SACKS FM, PFEFFER MA, MOYE LA, ROULEAU JL, RUTHERFORD JD, COLE TG, BROWN L, WARNICA JW, ARNOLD JM, WUN CC, DAVIS BR, BRAUNWALD E: The effect of pravastatin on coronary events after myocardial infarction in patients with average cholesterol levels. Cholesterol and Recurrent Events Trial investigators. N Engl J Med 335: 1001-1009, 1996.

SANADA S, ASANUMA H, MINAMINO T, NODE K, TAKASHIMA S, OKUDA H, SHINOZAKI Y, OGAI A, FUJITA M, HIRATA A, KIM J, ASANO Y, MORI H, TOMOIKE H, KITAMURA S, HORI M, KITAKAZE M: Optimal windows of statin use for immediate infarct limitation: 5'-nucleotidase as another downstream molecule of phosphatidylinositol 3-kinase. Circulation 110: 2143-2149, 2004.

SCANDINAVIAN SIMVASTATIN SURVIVAL STUDY GROUP: Randomised trial of cholesterol lowering in 4444 patients with coronary heart disease: the Scandinavian Simvastatin Survival Study (4S) Lancet 344: 13831389, 1994.

TAVACKOLI S, ASHITKOV T, HU ZY, MOTAMEDI M, URETSKY BF, BIRNBAUM Y: Simvastatin-induced myocardial protection against ischemia-reperfusion injury is mediated by activation of ATP-sensitive $\mathrm{K}^{+}$ channels. Coron Artery Dis 15: 53-58, 2004.

TIEFENBACHER CP, KAPITZA J, DIETZ V, LEE CH, NIROOMAND F: Reduction of myocardial infarct size by fluvastatin. Am J Physiol 285: H59-H64, 2003.

WAYMAN NS, ELLIS BL, THIEMERMANN C: Simvastatin reduces infarct size in a model of acute myocardial ischemia and reperfusion in the rat. Med Sci Monit 9: BR155-159, 2003.

WOLFRUM S, DENDORFER A, SCHUTT M, WEIDTMANN B, HEEP A, TEMPEL K, KLEIN HH, DOMINIAK P, RICHARDT G: Simvastatin acutely reduces myocardial reperfusion injury in vivo by activating the phosphatidylinositide 3-kinase/Akt pathway. J Cardiovasc Pharmacol 44: 348-345, 2004.

YAMAKUCHI M, GREER JJ, CAMERON SJ, MATSUSHITA K, MORRELL CN, TALBOT-FOX K, BALDWIN WM, LEFER DJ, LOWENSTEIN CJ: HMG-CoA reductase inhibitors inhibit endothelial exocytosis and decrease myocardial infarct size. Circ Res 9: 1185-1192, 2005.

ZHENG X, HU SJ: Effects of simvastatin on cardiohemodynamic responses to ischemia-reperfusion in isolated rat hearts. Heart Vessels 21: 116-123, 2006. 